\title{
THE PROBLEM OF VALUES IN PSYCHIATRY: A CONTRIBUTION OF PHILOSOPHY TO MEDICAL EDUCATION
}

\author{
Luca Ceraolo \\ University of Torino, Italy \\ E-mail: luca.ceraolo98@gmail.com \\ Mateja Ploj Virtič \\ University of Maribor, Slovenia \\ E-mail: mateja.plojvirtic@um.si
}

\begin{abstract}
Even though medical ethics has recently become a rather prominent area in healthcare, there are still institutions in some European countries where mentally ill patients are treated inhumanely. In order to help abolish such institutions, it is fundamental to further emphasize human ethics and ensure that it is duly taken into account - where necessary - medical education. A deep philosophical analysis of how we can improve medical education through appropriate modern approaches has been done. Prior research has shown that implementing what we call a holistic model grounded on interdisciplinarity into higher education significantly improves and deepens the level of knowledge. Basing on the importance of educational constructivism and the integration of history and philosophy of science in science education, there is a potential to improve medical education. The research aims to present a philosophical and historical reflection on psychiatry and to provide the guidelines to improve medical education. In particular, it is discussed the problem of value-ladenness in psychiatry from two different perspectives. The first, developed by the contemporary philosopher Rachel Cooper, points out how this commitment to values not only generates questions regarding the definition and the characterization of mental disorders, but also influences the epistemology of psychiatry in empirical research and methods. The second regards the more continental-influenced philosophical thought of the Italian psychiatrist Franco Basaglia, who succeeded in changing the educational and therapeutic practices in the relationship between health workers and patient. The concept of "meeting" is fundamental to translate Basaglia's suggestions in new guidelines for contemporary medical education.

Keywords: medical education, medical ethics, philosophy of science, science education, value-ladenness in psychiatry
\end{abstract}

\section{Introduction}

Living in a time of extremely rapid development and social change requires constant adaptation, not only of the individuals but also of institutions and processes, such as education. This is why the task of developing interdisciplinarity as one of the key requirements of the society that the 
education system, regardless of the level, subject area of education or cultural environment, must be accomplished. Although a great shift towards interdisciplinarity has been done in the last 20 years through integrated research institutes where interdisciplinary research is automatically a part of the research agenda (Klaassen, 2018), the universities are a rather rigid systems, where study programs have only been updated in recent years in the direction of increased interdisciplinarity. Interdisciplinary trends in research also surface in publication data, where more than one-third of the references in scientific papers are towards other disciplines (Ledford, 2015).

How can interdisciplinary education, in particular, be conducted in the best possible way? Flogie et al. (2015) refer that neuroscientific perspective on learning adds a new, important dimension to the study of learning in education, and educational knowledge could help direct neuroscience research towards more relevant areas. A human body is an extremely complex mechanism that, in addition to the complex physical body, encompasses other aspects such as personality, spirituality, culture, ... as well. To treat the people as a whole, medical education has to involve, besides narrow medical knowledge, also the levels, which are defining other social science aspects (see Figure 1). It can be called a holistic approach to the philosophical basis of health care.

\section{Figure 1}

The Levels of the Analysis and Relations Between Them

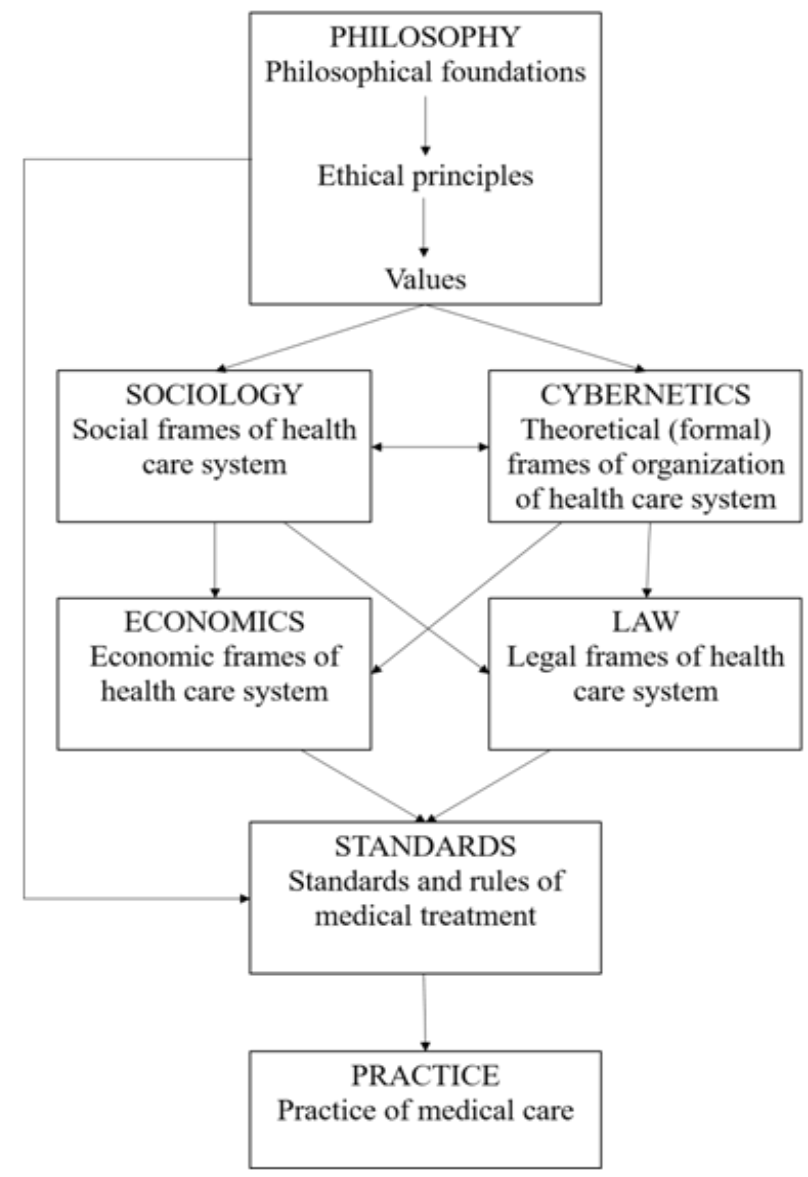

Note: (Bielecki \& Nieszporska, 2017).

Psychiatric diagnoses, methods and research are also shaped by culture, norms and values, therefore it seems psychiatry can't pretend to be defined as a merely descriptive and naturalistic science. The philosophical level is the most basic one. A requirement for physicians to learn about cultural and linguistic competence will allow them a better understanding of different race, culture and also consequently developing empathy that is very important when working with people (Garcia, 2006). 
OF PSYCHOLOGY

IN THE $21^{\text {st }}$ CENTURY

Vol. 14, No. 2, 2020

104

\section{Theoretical Background: The Importance of Constructivism and Philosophy of Science in The Education}

According to the challenge of 'science for all', British science educators considered what the next phase in school science might be like.

"The science curriculum should provide young people with an understanding of some key ideas about science, that is, ideas about the ways in which reliable knowledge of the natural world has been, and is being, obtained“" (Millar \& Osborne, 1998, p. 20).

The ideas of science education for the future, as set out above, are very much in line with the definition of constructivism in education by Aberšek (2008), which is emphasizing learning about scientific concepts. Matthews (1998) defined educational constructivism as an expansion of theoretical constructivism by incorporating views about epistemology, teaching, curriculum, ethics, and the cognitive claims of science. Educational constructivism necessarily involves considerations of philosophy, which is, by Boniolo et al. (2019), very important in medical education. Philosophy of Science (hereafter PS) is recognized as an important part of scientific knowledge, which improves science teachers' competence for teaching science in a wider context with many theoretical and educational debates. Many research was done on History and Philosophy of Science (hereafter HPS) in science teaching in the last 20 years (Bächtold \& Munier, 2019; Henke \& Höttecke, 2015; Matthews, 1998; Matthews, 2014; Maurines \& Beauflis, 2013; Monk \& Osborne, 1996; Pearce, 2018). Inclusion of HPS in the curricula and classroom teaching are not the sole solution to the 'problems of science education' but is making the subject more 'appealing', providing a broader understanding of the context, and better connected with other subjects being learned (Matthews, 2014; Monk \& Osborne, 1996; Solomon et al., 1992).

Apart from better learning of science, Matthews (2014) has stated that the inclusion of HPS in science curriculum as well as in science teaching can have significant impacts on people's worldviews and their religious and cultural understandings.

Similarly, as Spike (1991), authors note that it is very important for medical students, and all medical workers, who will work in the health system, to make historical and philosophical reflections, not only to study the science subjects but to be aware of how culture could change the consideration you have of who should be a patient. This claim could be strengthened by the consideration that "In ethics, values play a decisive role, and there are often no right or wrong opinions since everyone can assign different weights to different values." (Zwitter, 2019, p. 1). This role assigned to value-laden enquiry, as Ellis (2019, p. 984) argued, "is an important issue", which conveys the necessity of being incorporated "within medical education to promote reflection towards medicine's normative underpinnings".

\section{Research Aim}

There still exist institutions in some European countries where mentally ill patients are treated inhumanely. In order to help abolish such institutions, it is necessary to further emphasize human ethics and values to ensure that it is duly taken into account where necessary - medical education. The importance of educational constructivism and the integration of history and philosophy of science in science education expresses a potential to improve medical education.

The research aims to provide a philosophical and historical reflection on psychiatry and the guidelines to realize this improvement in medical education. An overlook on the philosophical problem of values in psychiatry could help to answer the question: "How to prepare/educate physicians to treat mental patients with compassion and respect?".

\section{Research Methodology}

Basing on the theoretical review on Philosophy of Science, it has been explored the impact 
of educational constructivism on science education. A deep analysis of philosophical and historical reflection on psychiatry and the problem of values have led to the solution of a holistic model grounded on interdisciplinarity in higher education.

\section{The Problem of Values: Philosophical Reflection}

To begin with, it is necessary to discuss five different functions $(\mathrm{F})$ that philosophy could acquire in relation to psychiatry. The first four $F$ have been detected by Lalumera (2018), who made this division according to different suggestions derived from several authors and can be placed within analytic philosophy. The last dates back to the 20th century phenomenological approach towards psychiatry:

i. Philosophy as methodological scepticism (Fulford, 2013; Jasper, 1913 in Lalumera, 2018)

ii. Philosophy as Psychiatry (Bortolotti, 2010; Bortolotti, 2015 in Lalumera, 2018; Davies \& Davies, 2009)

iii. Philosophy as an investigation on values (Charaland, 2006; Fulford et al., 2004; Malatesti \& McMillan, 2014; Szasz, 1961; Wakefield, 1999 in Lalumera, 2018)

iv. Philosophy of Science applied to Psychiatry (Amoretti, 2015; Bolton, 2000; Campaner, 2016; Campbell, 2008; Castiglioni \& Laudisa, 2015; Cooper, 2014; Kendler, 2005; Kendler, 2012; Lalumera, 2016; Murphy, 2006; Woodward, 2008 in Lalumera, 2018)

v. Phenomenological Psychiatry

According to $F(\mathrm{i})$, philosophy should work posing questions of methodological and grounding character, feeding doubts and leading to critical analysis. $F$ (ii) refers to a vision where philosophy works together with an empirical science sharing common problems (e.g. about philosophy and psychiatry: personal identity, consciousness, free will etc.). As far as $F$ (iii) is concerned, it points out how psychiatric issues are deeply connected with ethics, and consequently how mental illness and therapies implies a normative component which should take into account the individual within society. $F(\mathrm{iv})$ is the application of theoretical instruments of philosophy in order to clarify questions such as: "What is mental illness and how should we characterize it?", "Which is the metaphysical status of 'schizophrenia'?", "Which is the best explanation in psychiatry?", etc. In this sense, the semantic shade is that of a philosophy of a special science, just as a philosophy of physics/mathematics/biology/medicine exist (Gifford, 2011; Lemoine et al., 2014 in Lalumera, 2018). In conclusion, $F(\mathrm{v})$ assumes as an object of enquiry the subjectivity of the patients rather than the brain studied under an organicistic perspective. This school owes its development to the continental philosophy tradition, in particular to Martin Heidegger and Edmund Husserl.

Despite the fact that these possible functions refer to various ways of application of philosophy to psychiatric issues, we would argue that (a) there should not be strict separation as there are cases where methods or investigated issues just differ for subtle hints, and (b) that, in order to develop a global awareness of the complexity and of the possibility of a dialogue between philosophy and psychiatry, these different approaches should be integrated to structure an inclusive theoretical perspective able to take into account contributions from any discipline (psychiatry and philosophy themselves, but also biology, neuroscience, psychology, anthropology, and history. This goal might be accomplished just with an intervention on education) and capable of being translated in proper practice.

In support of this arguments, as the crucial aim of this section is to give evidence of how the philosophical method can be applied to scientific issues, we will discuss the problem of value-ladennes (hereafter $\mathrm{VL}^{1}$ ) in psychiatry from two different perspectives: firstly, it will be examined 
OF PSYCHOLOGY Vol. 14, No. 2, 2020

106

how a contemporary philosopher, Rachel Cooper, analyzes this point using the typical approach of analytic philosophy - a combination between $F($ iii) and $F($ iv) seems the correct characterization of her analysis; secondly, the paradigm will shift to the more continental-influenced philosophical thought of the Italian psychiatrist Franco Basaglia - that can be ascribed to $F(\mathrm{v})$ - who provoked a cultural revolution in the conception of mental illness and succeeded in changing the educational and therapeutic practices in the relationship between health workers and patients de-institutionalizing Italian asylums. This will enable us to give examples of the importance of integration between science and humanities through the powerful means of education and of the several kinds of philosophical concepts suitable for this kind of investigation.

\section{The Problem of Value-Ladenness (VL) in Cooper}

Cooper's concern on values within her metaphysical and epistemological inquiry will be introduced with a literary escamotage:

(I) Mr Smith hires Jones the Gardener, to take care of the plants of his new luxurious house.

"I don't hate anything more than dandelions! I want you to exclusively remove that infesting weed!".

Three elements are presented at the beginning of this story: Mr Smith, Jones the Gardener, and a plant. However, this plant is named twice by Mr Smith, who uses the term "dandelions" to specify which kind of plant he was referring to and "weed" that explicitly has a negative sense. This analogy with the natural world was suggested directly by Cooper (2013) who has intervened in the ongoing contemporary debate about whether it is possible to characterize mental disorders as natural kinds:

"Scientific disciplines frequently divide the particulars they study into kinds and theorize about those kinds. To say that a kind is natural is to say that it corresponds to a grouping that reflects the structure of the natural world rather than the interests and the actions of human beings." (Bird \& Tobin, 2018)

So the real issue at stake is if it is possible to reduce psychiatry and its component to a merely descriptive science grounded on natural basis and capable to treat mental illnesses as natural kinds, which "is worthwhile because such kinds can ground explanations and predictions and enable us to gain control over a domain" (Cooper, 2013, p. 950). However, the same attempts to define mental disorders have produced results which create a tension between values and nature, culture and science, mental disorders and natural kinds:

"On many accounts, a condition is only a disorder if it is a bad thing. Given that disorders are defined partly in value terms, but that natural kinds need to be defined with regard to natural properties, it may thus look like types of disorder cannot be natural kinds." (Cooper, 2013, p. 955)

To give evidence for this argument it is sufficient to consider the definition of mental disorders given by APA (American Psychiatric Association), where is clearly highlighted this commitment to values and cultural shaping 2 .

To confront this problem, Cooper (2013) makes an analogy that can be illustrated with the first passage of the brief story of Mr Smith and Jones. The British philosopher would remark that despite Mr Smith uses the umbrella category "weed" to indicate dandelions, the term "dandelions"

2 "A mental disorder is a syndrome characterized by clinically significant disturbance in an individual's cognition, emotion regulation, or behaviour that reflects a dysfunction in the psychological, biological, or developmental processes underlying mental functioning. Mental disorders are usually associated with significant distress or disability in social, occupational, or other important activities" (American Psychiatric Association, 2013, p. 20) 
itself could still fit the conditions to be included in the natural kinds. For this reason, even if the umbrella category "mental disorders" is partly defined in terms of values, the single manifestations (e.g. schizophrenia) could still be considered natural kinds in the same way of dandelions. This suggests that the problem of values is somehow related to language, the use of VL terms and to their extension.

Let's come back to the story to better expose this point:

(II) Mrs Smith returns home and meets Jones, the Gardener. Noticing that he is removing dandelions, she asks for an explanation.

"These are the instructions your husband gave me, madame."

"Please, stop! Dandelions aren't weeds. In fact, they are really useful both for therapeutic properties and for cooking. Could you please keep them for me?"

As Mrs Smith is aware of dandelions advantages, she would never categorize them as "weeds". Nevertheless, this should not always be the case of a term such as "schizophrenia" whose concepts "are insufficiently defined for it to be clear whether the term is itself value-laden, or whether it is a purely descriptive term that falls under a value-laden umbrella category" (Cooper, 2013, p. 955).

What emerges is that in the case of psychiatry domain there is ambiguity in the words used and difficulty in establishing the boundaries that detect their semantic reference - that is to say what a concept applies to. Moreover, as language turned out to be VL, we shall now ask whether psychiatry as a science in its empirical research and methods could result in VL or not. The story continues as follows:

(III) While working, Jones notices that the garden is also full of poppies and he wonders whether he should uproot those weeds too. Eventually, he desists and simply decides to follow his employer requests.

(IV) In the meanwhile, in another possible world (W*) Mr Smith* doesn't give Jones* any specific instructions. In the evening, however, Jones* is a strange gardener, Mr Smith* is surprised by the fact that Jones* has removed just dandelions. The reason is that Jones* has grown up with the conviction that the only weeds are exactly dandelions.

Before grasping the philosophical suggestions that this part could reflect, it is worthy to give a definition of VL: “... to say that a science is VL is to say that the theories developed have been shaped by the values of scientists" (Cooper, 2007, p. 127). Taking under examination psychiatry as a science, Cooper underlines how an engagement to values is possible at different levels of psychiatric empirical research.

Section III of the new little chapter of the story focalizes on the first stage of enquiry that is picking the research area (Cooper, 2007): Jones simply decides not to consider poppies as a problem for his job because Mr Smith explicitly asked him to eliminate just dandelions. In a similar way, research need to be funded and who lavish funds is usually in a position of power in relation to the researcher, so able to influence researchers on what to focus on. Cooper reported historical examples of studies on mental illness led among immigrants in the period 1900-1930, which are ideal to show how psychiatry could be VL: what mattered was the urgent issue of immigration as what matters to Mr Smith is the urgent need to extirpate dandelions and not poppies. Another example adduced by Cooper is that nowadays psychiatric therapy is fundamentally based on drugs, leading people to believe that this is the best solution even if it is not necessarily the case (Cooper, 2007).

As regards section IV, it is addressed to formulating a hypothesis to be tested (Ivi), another phase of psychiatry analysed as a science. As the definition of VL suggests, empirical research can be shaped by the convictions, beliefs and values of the scientist him/herself, so that the same starting hypothesis is already compromised by culture and norms.

Cooper led a comprehensive analysis of the problem of VL in psychiatry as a science exam- 
OF PSYCHOLOGY Vol. 14, No. 2, 2020

ining also the steps of assessing evidence and of presenting and using findings (Ibidem). The first concept arises problems related to the arbitrary choice of the psychiatrist on who is to be included in the mentally ill category, and therefore to make diagnosis based on doctor's expectations; another problem is the interpretation of collected data, manipulable according to the variables taken into consideration and to the corrections that scientists could make; in conclusion, another VL issue is the reliability of witnesses, often dependent on a hierarchy modelled by social considerations.

About presenting findings it is important to say that - as previously mentioned but still to properly develop - language is VL and tend to stigmatize the people it refers to, whereas in using findings "... research is commissioned by parties who are not interested in discovering the truth about some question but who merely want to use the rhetorical power of science to justify decisions that have already been made on other grounds" (Cooper, 2007, p. 135-136).

To summarize, the problem of VL in psychiatry from Cooper's perspective has been discussed, highlighting how it generates and how it turns to psychiatry as a science in its empirical research. However, the research needs also to address to psychiatric method in its theoretical component, namely observation.

In Classifying Madness: A Philosophical Examination of the Diagnostic and Statistical Manual of Mental Disorders, Cooper (2005) distinguished between three kinds of observation in psychiatry: perception, language and classification. Language could be identified as the fulcrum for what follows, because it constitutes an effective example of how the application of philosophical analysis to scientific issues could succeed in finding a solution to a part of the problem. Cooper illustrates how "Those philosophers who claim that language is necessarily theory-laden [hereafter TL] claim that the meanings of the terms used in an observation statement are at least partially dependent on a theory" (Cooper, 2005, p. 87). To make a clear example, which recalls The Logic of Scientific Discovery (Popper, 1959), imagine that someone says: "This is a dandelion". This statement implies a lot of previous knowledge (what a dandelion is, how it looks like, the physical properties that permit to distinguish it from a poppy etc.) and clearly shows in what sense language is actually TL.

However, the best way Cooper identifies to overcome the problem of TL for language is claiming that: "the theories assumed by the observation statement that reports the result of an experiment will generally be different from the theory that the experiment is testing" (Cooper, 2005, p. 88), which is what she calls Nagel's Suggestion (Nagel, 1971). Therefore, all observation statements are TL, but it is still possible for scientists with different theoretical backgrounds to signify the same thing by an observation statement. This means that in a hypothetical meeting between a biologist and Jones*, even if the first claims: "This is Taraxacum officinale", and the second: "This is an infesting weed", they would both mean: "This is a dandelion". The same, concludes Cooper, is valid for psychiatry in a dialogue between a psychoanalyst and a biologically-orientated psychiatrist:

"So long as the theories assumed by a description do not include those theories about which the scientists disagree, their different theoretical beliefs will not lead to any difference in meaning (therefore) they should experience no problem in communicating." (Cooper, 2005, p. 88)

\section{Meeting as a Model of The Therapeutic Relationship in Basaglia}

Franco Basaglia $^{3}$ (1924-1980) was deeply influenced by a vast cultural background ${ }^{4}$. This is why the Italian reviewer of the psychiatric system can be presented as an example of method towards science which attains to continental philosophy and, indeed, anthropology.

3 Italian psychiatrist who conducted a revolution between ' 60 s and ' 70 s that ended up in the approval of Law 180 (1978) which established the closure of asylums, total institutions (Goffman, 1961), in Italy.

4 This can be ascribed to Marxism, Phenomenology and Existentialism and to the contacts he entertained with the anti-psychiatrist movement, anthropologists, sociologists and philosophers. In particular: Marx, Heidegger, Husserl, Jaspers, Sartre, Foucault, Fanon, Laing, Szasz, Goffman, Minkowski, Binswanger et al.

For a comprehensive introduction to Basaglia biography, theory and practice we suggest an article by John Foot (Foot, 2014), which also analyses the historical circumstances for the missing translation of Basaglia works in the Englishspeaking world. 
The fil rouge will be the same problem of VL, that Basaglia identified through an analysis shaped on Marxist categories. In addition, it will be briefly exposed the proposal for a new concepVol. 14, No. 2, 2020 tion of psychiatric therapy that outlines how Basaglia, feeding his scientific practice in psychiatry with theoretical stimuli that can be placed under the cathegory of "humanities", extended his interest from the domain of medicine to the social, cultural and psycho-pedagogical ones (Goussot, 2011).

Firstly, it is crucial to underline how for the Italian psychiatrist the total institutions are created by capitalistic system in order to alienate the mentally-ill individuals, who are simply reduced to their diagnoses: "in the capitalistic society the norm is defined in terms of productivity and mental illness is, as Foucault claims, 'absence of work', impossibility to produce, disturb of productivity" (Foucault, 1964; Goussot, 2011, p. 239). This process controls and produces disease and an "ideology of diversity" (Goussot, 2011) which reflects on language its values and norms:

“... language conveys regulatory codes and creates taxonomies. The technical language of sociologists, anthropologists, educators, psychologists and psychiatrists, rather than being neutral, has a precise function in social relationships and justifies the organized control of human beings who are transformed in patients." (Goussot, 2011, p. 242)

By saying that individuals are transformed in patients, Basaglia doesn't intend "that illness doesn't exist, but that we produce symptomatology according to the way we want to manage it within the social and political context" (Basaglia, 1975). Furthermore, it seems plausible to argue that language and medical practice are VL also from his point of view.

Deeply involved in medical praxis, Basaglia translated these critiques to the psychiatric model into a new attempt of therapy whose aim was changing the relationship between doctor/ health worker and patient: "The ill and the illness can't be considered as objectified data of science as far as they concern the whole personalities together with the systems of values and beliefs both of the patient and the therapist in the cure relation" (Goussot, 2011, p. 254). It turns out that language, despite being VL, can be re-semanticized to let the meeting happen through dialogue and intersubjective reciprocity.

The concept of meeting is the fundamental contribution given by Basaglia to the new way of therapeutic practice and derives from the suggestions of Jasper's "comprehensive psychology" as phenomenological investigation (Jasper, 1913) and Binswanger's Daseinanalyse (Binswanger, 1953). When the doctor and the patient meet, therapy goes through recognizing the living experience of the latter in order to comprehend the person in his/her psycho-social meaning rather than the delusion:

"There is no possibility for psychological comprehension of an individual without living the way the individual has conceived the world." (Basaglia, 1953, p. 52).

\section{Conclusions and Recommendations}

The discussion focused on a philosophical problem faced by science together with the exposition of two different points of view. The aim was to render evident the exigence of combining science education with humanities in order to broaden students' horizons and to give them the instruments to face the complexity of the system we live in.

The research points out that there are at least two benefits derive from this science-humanities educational integration: on the one hand, it enables not only to train professionals (doctors/nurses/ health workers etc.) with a properly developed problem-solving faculty, but especially to train people who should be aware they aren't just dealing with mechanical bodies but with other human beings in their different personal and social aspects (as depicted in Figure 1); on the other hand, the same humanistic methodologies could present solutions to the problems raised in science exploiting their different theoretical instrumentation (e.g. the Nagel's Suggestion identified by Cooper to sidestep the problem of VL in language or the meeting as therapy for mentally ill patients implemented by Basaglia).

As it was noticed, the exigence of philosophical reflection within the educational medical 
OF PSYCHOLOGY Vol. 14, No. 2, 2020

110

system emerges because methodology and ethics are domains committed with real life. The suggestion and hope for the future are therefore not only to put in dialogue science and philosophy throughout education but also that the prior instruments for critical analysis received from the academy could be developed and deepened by field-working. Reason and experience should be in a mutual exchange in this ongoing dynamics, keeping on enriching reciprocally.

\section{Acknowledgement}

The authors acknowledge the financial support from the Ministry of Education, Science and Sport of the Republic of Slovenia and the European Social Fund for support the project 'Innovative Pedagogy 1:1 in Light of 21st Century Competencies', and the Slovenian Research Agency for support to the core project 'Computationally intensive complex systems', grant no. P1-0403 (Ploj Virtič Mateja).

\section{References}

Aberšek, B. (2008). Future for science and engineering education. Problems of Education in the 21st Century, 6, 9-17. http://www.scientiasocialis.1t/pec/node/106

American Psychiatric Association. (2013). Diagnostic and statistical manual of mental disorders (DSM-5®). American Psychiatric Publications.

Amoretti, M. C. (2015). Filosofia e medicina [Philosophy and medicine]. Carocci.

Bächtold, M., \& Munier, V. (2019). Teaching energy in high school by making use of history and philosophy of science. Journal of Research in Science Teaching, 56(6), 765-796. https://doi.org/10.1002/tea.21522

Basaglia, F. (1953). Il mondo dell' «incomprensibile» schizofrenico attraverso la Daseinanalyse. Presentazione di un caso clinico [The world of the "incomprehensible" schizophrenic through the Daseinanalyse. Presentation of a clinical case]. Giornale di Psichiatria e di Neuropatologia, 81, 471-499. http://www.nilalienum.it/ Sezioni/Antipsichiatria/Basaglia/1.html

Basaglia, F. (1975). Ideologia e pratica in tema di salute mentale [Ideology and practice in mental healthcare]. In Basaglia, F. (Ed.), Scritti. 1953-1980 [Essays. 1953-1980] (pp. 803-810). Il Saggiatore.

Bielecki, A., \& Nieszporska, S. (2017). The proposal of the philosophical basis of the health care system. Medicine, Health Care and Philosophy, 20(1), 23-35. https://doi.org/10.1007/s11019-016-9717-2

Binswanger, L. (1953). Grundformen und Erkenntnis Menschlichen Daseins [Formative principles and knowledge of human existence]. Ernst Reinhardt Verlag.

Bird, A., \& Tobin, E. (2018). Natural Kinds. (E. Zalta, Editor). The Stanford Encyclopedia of Philosophy. https:// plato.stanford.edu/archives/spr2018/entries/natural-kinds/

Bolton, D. (2000). Alternatives to disorder. Philosophy, Psychiatry, \& Psychology, 7(2), 141-153. https://muse. jhu.edu/article/28338

Boniolo, G., Campaner, R., \& Coccheri, S. (2019). Why include the humanities in medical studies? Internal and Emergency Medicine, 14(7), 1013-1017. https://doi.org/10.1007/s11739-019-02131-2

Bortolotti, L. (2010). Delusions and other irrational beliefs. Oxford University Press.

Bortolotti, L. (2015). The epistemic innocence of motivated delusions. Consciousness and Cognition, 33, 490-499. https://doi.org/10.1016/j.concog.2014.10.005

Brush, S. G. (1989). History of science and science education. Interchange, 20(2), 60-70. https://doi.org/10.1007/BF01807048

Campaner, R. (2016). Mechanistic models and modeling disorders. In E. Ippoliti, E. Sterpetti, \& T. Nickles (Eds.), Models and inferences in science (pp. 113-132). Springer International Publishing.

Campbell, J. (2008). Causation in psychiatry. In K. Kendler, \& J. Parnas (Eds.), Philosophical issues in psychiatry. Explanation, phenomenology, and nosology (pp. 196-216). The Johns Hopkins Press.

Castiglioni, M., \& Laudisa, F. (2015). Toward psychiatry as a 'human'science of mind. The case of depressive disorders in DSM-5. Frontiers in Psychology, 5, 1-12. https://dx.doi.org/10.3389\%2Ffpsyg.2014.01517 
Charaland, L. C. (2006). Moral nature of the DSM-IV Cluster B personality disorders. Journal of Personality Disorders, 20(2), 116-125. https://doi.org/10.1521/pedi.2006.20.2.116

Cooper R., V. (2007). Psychiatry and philosophy of science. McGill-Queen's University Press.

Cooper, R. (2013). Natural kinds. In K. Fulford, D. M., G. G., S. J., G. Stanghellini, \& T. Thornton (Eds.), Oxford Hanbook of Philosophy and Psychiatry (pp. 950-964). O.U.P.

Cooper, R. (2014). Diagnosing the diagnostic and statistical manual of mental disorders. Karnac Books.

Cooper, R. V. (2005). Classifying madness. Springer.

Davies, A., \& Davies, M. (2009). Explaining pathologies of belief. In M. R. Broome, \& L. Bortolotti (Eds.), Psychiatry as cognitive neuroscience: Philosophical perspectives (pp. 285-326). Oxford University Press.

Ellis, R. D. (2019). The role of values in scientific theory selection and why it matters to medical education. Bioethics, 33(9), 984-991. https://doi.org/10.1111/bioe.12612

Flogie, A., Dolenc, K., \& Aberšek, B. (2015). Transdisciplinarity in education is near. In.: Lamanauskas V., Šlekienè

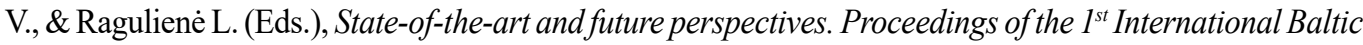
Symposium on Science and Technology Education (BalticSTE2015) (pp. 45-47). Scientia Socialis Press.

Foot, J. (2014). Franco Basaglia and the radical psychiatry movement in Italy, 1961-1978. Critical and Radical Social Work, 2(2), 235-249. https://dx.doi.org/10.1332\%2F204986014X14002292074708

Foucault, M. (1964). La Folie, l'absence d'oeuvre. La Table Ronde. http://1libertaire.free.fr/MFoucault243.html

Fulford, K. W. (2013). The Oxford handbook of philosophy and psychiatry. OUP.

Fulford, K. W., Stanghellini, G., \& Broome, M. (2004). What can philosophy do for psychiatry? World Psychiatry: Official Journal of the World Psychiatric Association (WPA), 3(3), 130-135. https://www.ncbi.nlm.nih.gov/ pmc/articles/PMC1414692/

Garcia, R. S. (2006). Interdisciplinarity in medical education on race. Journal of the National Medical Association, 98(5), 811-813. https://pubmed.ncbi.nlm.nih.gov/16749662/

Gifford, F. (2011). Philosophy of medicine. Elsevier.

Goffman, E. (1961). Asylums: Essays on the social situations of mental patients and other inmates. Anchor Books.

Goussot, A. (2011). Franco Basaglia e l'ansia dell'incontro con l'Altro: l'approccio della deistituzionalizzazione [Franco Basaglia and the anxiety of the encounter with the Other: the approach of deinstitutionalization]. Educazione Democratica, 236-272. http://educazionedemocratica.org/?p=375

Henke, A., \& Höttecke, D. (2015). Physics teachers' challenges in using history and philosophy of science in teaching. Science \& Education, 24(4), 349-385. https://doi.org/10.1007/s11191-014-9737-3

Jasper, K. (1913). Allgemeine psychopathologie: ein leitfaden für studierende, ärzte und psychologen [General psychopathology: A guide for students, doctors, and psychologists]. Springer.

Kendler, K. S. (2005). Toward a philosophical structure for psychiatry. American Journal of Psychiatry, 162(3), 433-440. https://doi.org/10.1176/appi.ajp.162.3.433

Kendler, K. S. (2012). Levels of explanation in psychiatric and substance use disorders: implications for the development of an etiologically based nosology. Molecular Psychiatry 17(1), 11-21. https://doi.org/10.1038/mp.2011.70

Klaassen, R. G. (2018). Interdisciplinary education: A case study. European Journal of Engineering Education, 43(6), 42-859. https://doi.org/10.1080/03043797.2018.1442417

Lalumera, E. (2016). Saving the DSM-5? Descriptive conceptions and theoretical concepts of mental disorders. Medicina \& Storia, XVI(9-10), 109-128.

Lalumera, E. (2018). Filosofia della psichiatria [Philosophy of psychiatry]. APHEX, 17, 1-22.

Ledford, H. (2015). How to solve the world's biggest problems. Nature News, 525(7569), 308-311.

Lemoine, M., Darrason, M., \& Richard, H. (2014). Where is philosophy of medicine headed? A report of the International Advanced Seminar in the Philosophy of Medicine (IASPM). Journal of Evaluation in Clinical Practice, 20(6), 991-993. https://doi.org/10.1111/jep.12206

Malatesti, L., \& McMillan, J. (2014). Defending psychopathy: An argument from values and moral responsibility. Theoretical Medicine and Bioethics, 35(1), 7-16. https://doi.org/10.1007/s11017-014-9277-5 
Matthews, M. R. (1998). Constructivism in science education: A philosophical examination. Springer Science. Matthews, M. R. (2014). Science teaching: The contribution of history and philosophy of science. Routledge.

Maurines, L., \& Beauflis, D. (2013). Teaching the nature of science in physics courses: The contribution of classroom historical inquiries. Science \& Education, 22, 1443-1465. https://doi.org/10.1007/s11191-012-9495-z

Millar, R., \& Osborne, J. (1998). Beyond 2000: Science education for the future. Nuffield Foundation.

Millar, R., Osborne, J., \& Nott, M. (1998). Science education for the future. School Science Review, 80(291), 1924. (EJ580554). ERIC. https://eric.ed.gov/?id=EJ580554

Monk, M., \& Osborne, J. (1996). Placing the history and philosophy of science on the curriculum: A model for the development of pedagogy. Science Education, 81(4), 405-424. https://doi.org/10.1002/(SICI)1098-237X(199707)81:4<405::AID-SCE3>3.0.CO;2-G

Moussaoui, D. (2007). The challenge for medical ethics in the 21 st century is its education. Bulletin de L'Academie Nationale de Medecine, 191(1), 131-137.

Murphy, D. (2006). Psychiatry in the scientific image. The MIT Press.

Nagel, E. (1971). Theory and observation. Reprinted in Nagel E. (1979). Teleology revisited and other essays in the history and philosophy of science (pp. 29-48). Columbia University Press.

Pearce, J. (2018). Psychometrics in action, science as practice. Advances in Health Sciences Education, 23(3), 653-663. https://doi.org/10.1007/s10459-017-9789-7

Popper, K. (1959). The logic of scientific discovery. Hutchinson.

Solomon, J., Duveen, J., Scot, L., \& McCarthy, S. (1992). Teaching about the nature of science through history: Action research in the classroom. Journal of Research in Science Teaching, 29(4), 409-421. https://doi.org/10.1002/tea.3660290408.

Spike, J. (1991). The need for teaching philosophy in medical education. Theoretical Medicine, 12(4), 359-365. https://doi.org/10.1007/BF00489894

Szasz, T. (1961). The myth of mental illness. Harper \& Row.

Wakefield, J. (1999). Mental disorder as a black box essentialist concept: The concept of disorder: Evolutionary analysis and critique. Journal of Abnormal Psychology, 108(3), 465-472. https://doi.org/10.1037/0021-843X.108.3.465

Woodward, J. F. (2008). Cause and explanation in psychiatry: An interventionist perspective. In K. Kendler, \& J. Parnas (Eds.), Philosophical issues in psychiatry: Explanation, phenomenology, and nosology (pp. 132195). Johns Hopkins University Press.

Zwitter, M. (2019). Medical ethics in clinical practice. Springer Nature. https://doi.org/10.1007/978-3-030-00719-5

Received: October 20, 2020

Accepted: December 11, 2020

Cite as: Ceraolo, L., \& Ploj Virtič, M. (2020). The problem of values in psychiatry: A contribution of philosophy to medical education. Problems of Psychology in the $21^{\text {st }}$ Century, 14(2), 102-112. https://doi.org/10.33225/ppc/20.14.102

Luca Ceraolo BA in Philosophy, MA Student in Cultural Anthropology and Ethnology,

Department of Culture, Politics and Society, University of Torino, via

Sant'Ottavio 20, 10124, Torino, Italy.

E-mail: luca.ceraolo98@gmail.com

Mateja Ploj Virtič

(Corresponding author)
$\mathrm{PhD}$, Associate Professor, University of Maribor, Faculty of Natural Sciences and Mathematics, Koroška street 160, SI-2000 Maribor, Slovenia. E-mail: mateja.plojvirtic@um.si

ORCID: https://orcid.org/0000-0002-3340-7611 